\title{
Tribological Problems in the Space Development in Japan*
}

\begin{abstract}
Makoto NISHIMURA**
R\&D of launch vehicles, satellites and the Japanese Experiment Module to be connected to the Space Station is traced with special emphasis on their tribological problems encountered on the way of space development in Japan. Lubrication, friction and wear of rolling bearings and seals applied to turbopumps of an $\mathrm{LE}-5$, the first $\mathrm{LOX} / \mathrm{LH}_{2}$ engine completed in Japan, are discussed. Performance on orbit of ball bearings supporting the scanning mirrors of the earth sensors launched in 1981 is introduced including test results of candidate materials used for cages . Compared to conventional rolling bearings, magnetic bearings have the merit of no friction and wear. Results obtained from experiments of the magnetically supported flywheel brought into orbit in 1987 are described. Futhermore several tribological problems tribologists confront in designing the Japanese Experiment Module are refered.
\end{abstract}

Key Words : Lubricant, Solid Lubricant, Vacuum, Space, Ball Bearing, Bearing, Magnetic Bearing

\section{Introduction}

The advent of the space age in Japan arrived in 1970 when she succeeded in launching the first scientific satellite "Ohsumi" named after the peninsula where it was launched. Since then, 22 satellites for practical applications and 16 scientific satellites were put into orbit. This made Japan the third most experienced country in space in the world after the U.S. and the U.S.S.R.

A satellite is equipped with a number of moving parts and driving systems requiring lubrication: an antenna pointing system, a solar array drive mechanism, and various types of scanners, to name but a few. Figure 1 shows examples of rolling and sliding bearings used in the drive mechanisms of a typical three-axis controlled satellite. A solar battery paddle

* Received 2 nd June, 1988

** Space Technology Research Group, National Aerospace Laboratory, 7-44-1 Jindaiji-higashi-machi, Chofu, Tokyo, 182, Japan drive system shown in the figure, for example, has 14 ball bearings which are lubricated with solid lubricants. More than 50 rolling bearings in total are required to operate in a recent satellite, most of which call for solid lubrication. Therefore, durable solid lubrication is the key to operating satellites maintenance free for the required life span.

A solid or liquid propellant rocket, or their combination is used to put an orbiter into space. The most powerful and sophisticated launch vehicle to date employs a $\mathrm{LOX} / \mathrm{LH}_{2}$ propellant system. These cryogenic fluids supplied from storage tanks are pressurized by turbopumps, and fed to a combustion chamber to generate a thrusting force. The difficulties lie in how to lubricate ball bearings of turbopumps which are required to run, under certain circumstances, at rotational speeds of over $50000 \mathrm{rpm}$ while carrying a high load.

Sealing is also a critical technique especially for a LOX turbopump: it is well known that liquid oxygen becomes extremely dangerous when mixed with hydrogen or hydrocarbons. To avoid catastrophy, 
liquid oxygen to be sent by a turbopump should be completely separated from the hydrogen-rich combustion gas used to drive the turbine. Again, the importance of tribology in space technology is emphasized.

This article describes the Japanese space programs including the R\&D of satellites, launch vehicles and the Japanese Experiment Module to be connected to the U.S. Space Station with special emphasis on the tribological problems; it describes how they were solved by the Japanese tribologists and how they are to be challenged.

\section{Launch Vehicles}

\section{1 Rolling bearings}

Japanese scientific satellites have consistently been launched using solid propellant rockets. How. ever, solid thrusters are being replaced by launch vehicles using liquid fuels in the field of satellites for practical applications in order to meet demands for higher payloads.

The R\&D of the first liquid propellant rocket engine began in 1977. In 1981 this engine was, for the first time, used to launch the Experimental Test Satellite IV. Though the first stage engine was powered by the combustion of liquid oxygen and RJ-1, the thruster did not provide turbine pumps to feed the propellant and the oxidizer. Instead, the liquid fuels were supplied from tanks to the combustion chamber by use of static pressure.

Inevitably, the next goal set was the realization of a launch vehicle called $\mathrm{H}-\mathrm{I}$, utilizing the combustion of liquid oxygen and hydrogen. The $\mathrm{LOX} / \mathrm{LH}_{2}$ turbopump system for the engine of the second stage of an H-I was initiated in 1977. After some trial and error efforts, the first flight was successfully completed in 1986. Among other things, the most difficult task demanded of the engine system is to regenerate. thrusting power after a certain inactive interval so as to modify the orbit to the planned one. This technique is a key feature of the forthcoming $\mathrm{H}$ - II launch vehicle, a simple two-stage type vehicle instead of the threestage-type generally employed for this class.

Figure 2 compares outside views of an $\mathrm{H}-\mathrm{I}$ vehicle and an $\mathrm{H}-\mathrm{II}$ vehicle with that of an M-3 SII, a major means of transportation for scientific satellites $^{(1)}$. Details of these vehicles are given in Table $1^{(2)}$.

The H-II scheduled to make the first trial in 1991 would be able to place a 2-ton satellite into geostationary orbit. The first stage of the $\mathrm{H}$-II is to be powered by an engine named LE-7, which is presently developed. To reduce development costs, the secondstage engine of an $\mathrm{H}$-II utilizes the second stage engine of an $\mathrm{H}-\mathrm{I}$, called LE-5.

Generally speaking, the performance of a rocket

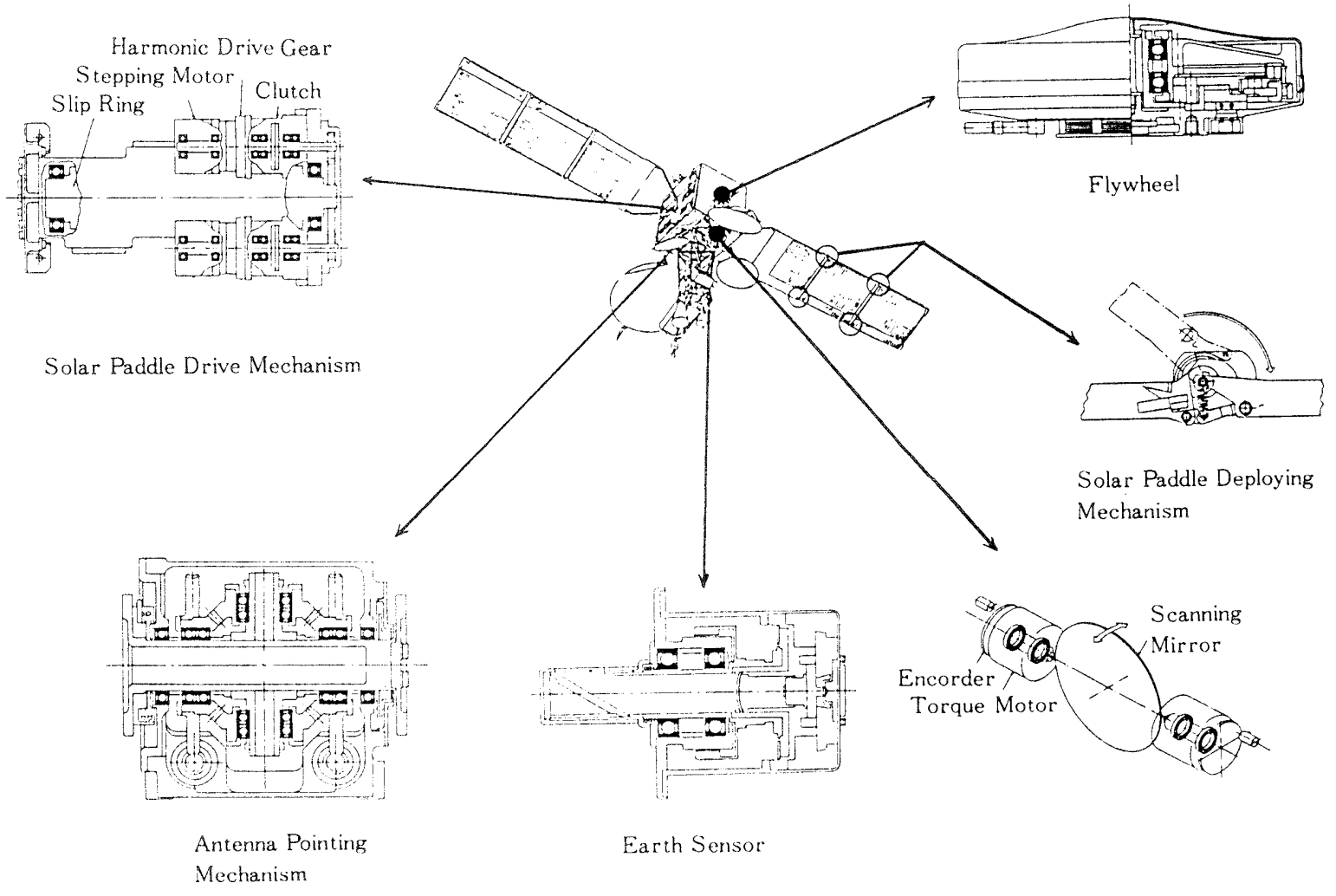

Fig. 1 Examples of rolling and sliding bearings used in a three-axis controlled satellite 
Table 1 Characteristics of $\mathrm{H}-\mathrm{I}$ and $\mathrm{H}-\mathrm{II}$ launch vehicles compared to M-3S II (2)

\begin{tabular}{|c|c|c|c|c|}
\hline & & M-3S II & $\mathrm{H}-\mathrm{I}$ & $\mathrm{H}-\mathrm{II}$ \\
\hline Payload Capabilty & $\begin{array}{l}\text { Geostationary Orbit } \\
\text { Oow Earth Orbit }\end{array}$ & $700 \mathrm{~kg}$ & $\begin{array}{c}550 \mathrm{~kg} \\
3,000 \mathrm{~kg}\end{array}$ & $\begin{array}{l}2 \mathrm{t} \\
7 \mathrm{t}\end{array}$ \\
\hline Dimensions & $\begin{array}{l}\text { Overall Length } \\
\text { Diameter }\end{array}$ & $\begin{array}{r}27.8 \mathrm{~m} \\
1.4 \mathrm{~m}\end{array}$ & $\begin{array}{l}40 \mathrm{~m} \\
2.4 \mathrm{~m}\end{array}$ & $\begin{array}{r}46 \mathrm{~m} \\
4 \mathrm{~m}\end{array}$ \\
\hline Lift off Weight & & $61 t$ & $140 \mathrm{t}$ & $240 \mathrm{t}$ \\
\hline 1st Stage & $\begin{array}{l}\text { Engine } \\
\text { Propellant }\end{array}$ & $\begin{array}{l}\text { M-13 } \\
\text { Solid }\end{array}$ & $\begin{array}{c}\mathrm{MB}-3 \\
\text { LOX/RJ-1 }\end{array}$ & $\begin{array}{c}\mathrm{LE}-7 \\
\mathrm{LOX} / \mathrm{LH}_{2}\end{array}$ \\
\hline Strap-on-Booster & $\begin{array}{l}\text { Motor } \times \text { Number } \\
\text { Propellant }\end{array}$ & $\begin{array}{l}\text { SB-735 } \\
\text { Solid }\end{array}$ & $\begin{array}{c}\text { Castor- II } \times 9 \\
\text { CTPB }^{*}\end{array}$ & $\begin{array}{l}\times 2 \\
\text { Solid }\end{array}$ \\
\hline 2nd S tage & $\begin{array}{l}\text { Engine } \\
\text { Propellant }\end{array}$ & $\begin{array}{l}\mathrm{M}-23 \\
\text { Solid }\end{array}$ & $\begin{array}{c}\mathrm{LE}-5 \\
\mathrm{LOX} / \mathrm{LH}_{2}\end{array}$ & $\begin{array}{c}\text { LE-5 } \\
\text { LOX-LH }\end{array}$ \\
\hline 3rd Stage & $\begin{array}{l}\text { Motor } \\
\text { Propellant }\end{array}$ & $\begin{array}{l}\text { M-3B } \\
\text { Solid }\end{array}$ & Solid & - \\
\hline
\end{tabular}

* Carboxy 1-Terminated Polybutadiene

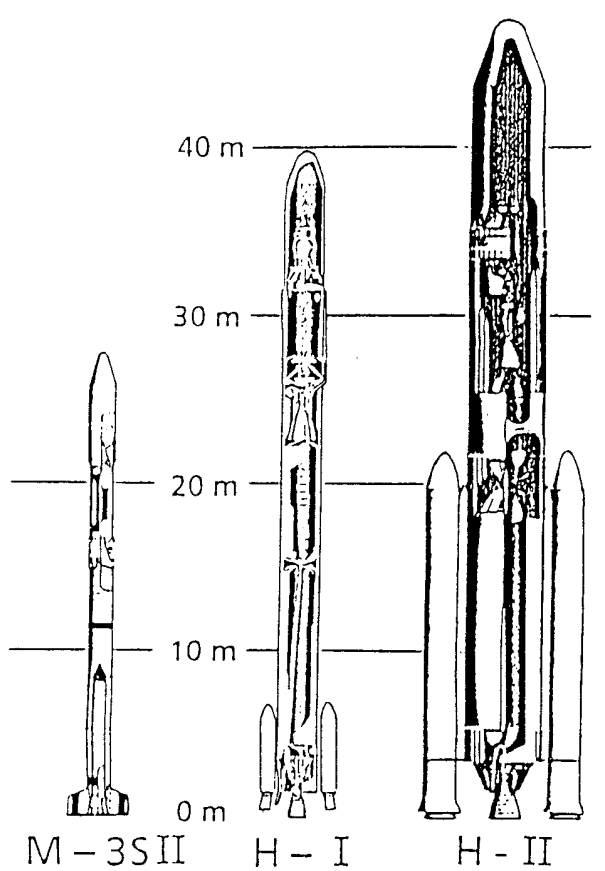

Fig. 2 Comparison of Japanese launch vehicles ${ }^{(1)}$ engine is markedly improved by the combustion of propellant at high pressures. For this purpose, turbopumps capable of operating at higher pressures are required. Turbopumps of an LE-7 engine are designed to run at $20000 \mathrm{rpm}$ at $22 \mathrm{MPa}$ for liquid oxygen and at $46000 \mathrm{rpm}$ at $32.7 \mathrm{MPa}$ for liquid hydrogen.

Figure 3 gives views of an LE-5 and an LE-7 engine ${ }^{(3)}$. The dn value of the rolling bearings of an $\mathrm{LH}_{2}$ pump for the LE- 7 reaches $1.8 \times 10^{6}$, comparable to that of the main bearings of a JT9D - the gas turbine used in a jumbo jet ${ }^{(4)}$. Characteristics of tur. bopumps of representative thrusters are compared in Table $2^{(5)}$.

Tribological problems of turbopumps used for supplying cryogenic fluids derive from the fact that one can not apply conventional oils or greases to lubricate them because of the low operating temperatures. In addition, cryogenic fluids are thought to be poor lubricants; their low viscosity does not afford sufficient fluid film to separate balls from races. Full fluid film lubrication is not possible. Furthermore, liquid hydrogen reduces protective metal oxide to metal, allowing bare metal-to-metal contact leading, 
Table 2 Operating conditions required to typical Lox $/ \mathrm{LH}_{2}$ turbopumps ${ }^{(5)}$

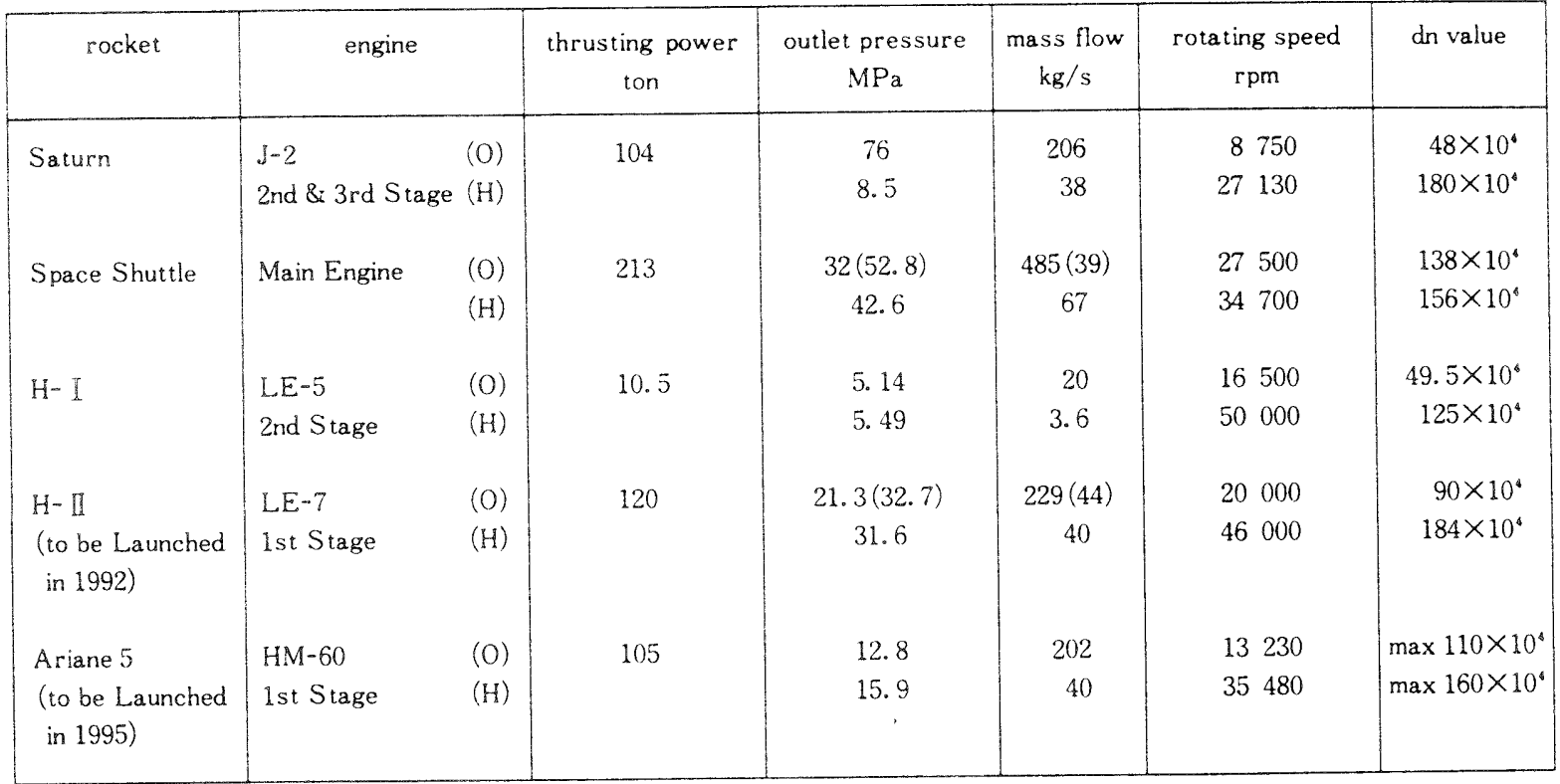

(O) : LOX Turbopump, (H) : LH Turbopump, ( ) : Preburner
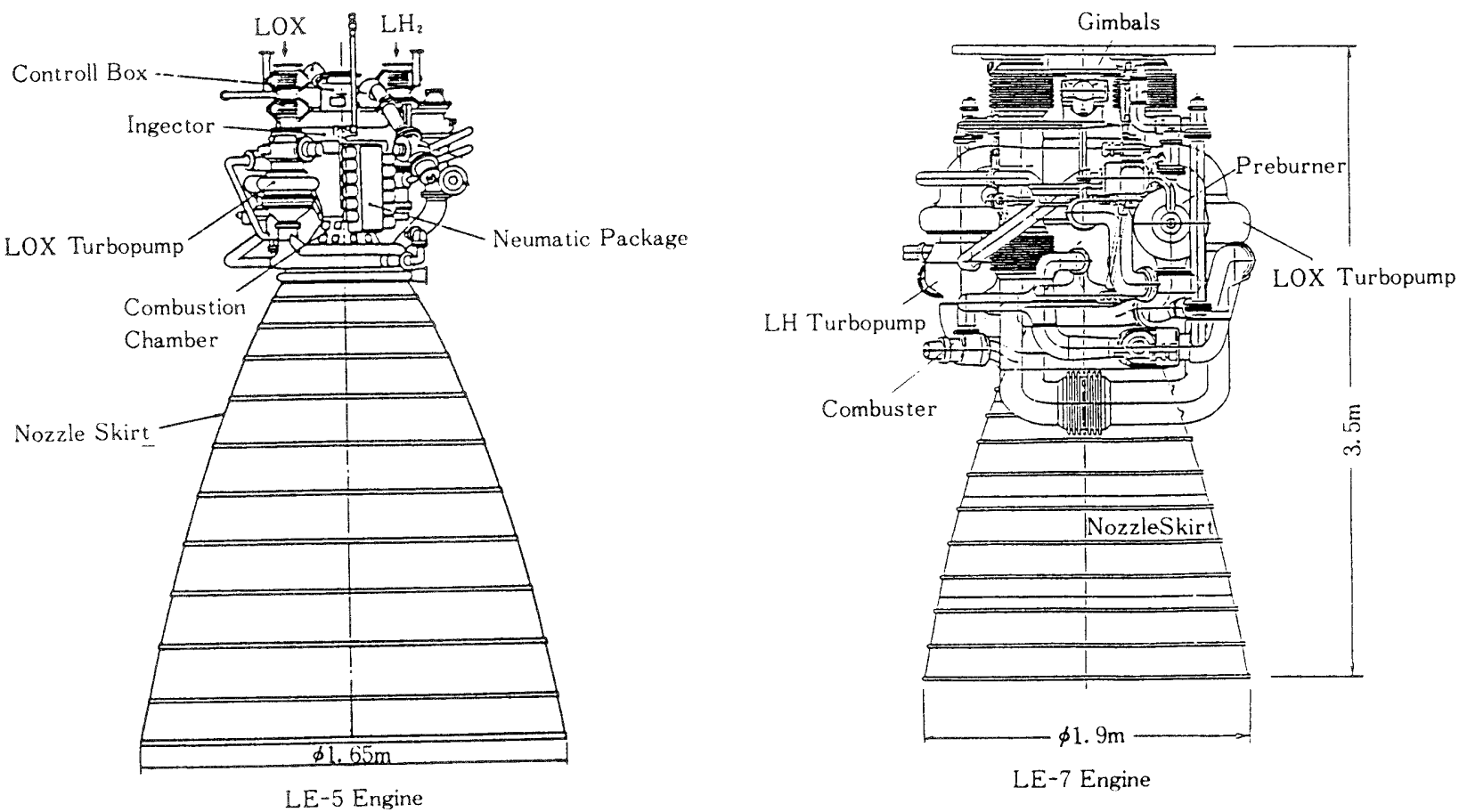

Fig. 3 Schematic diagram of an LE- 5 and an LE- 7 engine ${ }^{(3)}$

in the worst case, to seizure. In this respect, liquid oxygen is easier to handle. However, liquid oxygen becomes extremely explosive when mixed with oils. Thus, solid lubrication seems to be the only solution.

The ball bearings of the turbopumps for an LE-5 engine are lubricated by PTFE films transfered from retainers containing PTFE. This type of retainer material, basically composed of glass fiber or glass cloth as a reinforcement and PTFE as a solid lubri- cant, is currently applied to most cryogenic turbopumps for rocket engines as well as for industrial use.

Nosaka and his team have been carrying out extensive studies on tribological problems at cryogenic temperatures including the selection of cage materials and surface treatments of ball bearings for turbopumps of rocket engines ${ }^{(6)}$. The selected combination by them for an LE-5 satisfied the requirements in 
most cases when applied to practical bearings but sometimes showed an unexpected rise in outer race temperature, presumably caused by the insufficient transfer of PTFE from the retainers to the balls and races. Careful observations of these surfaces revealed that glass fibers extruded from the surfaces of retainer pockets scraped the PTFE lubricating films off of the surfaces of the balls.

To eliminate this harmful effect, they tried to remove the glass fibers from the surfaces of the ball pockets. For this purpose, they pretreated the cages with acid. This particular process consists of dipping cages in hydraulic fluoride for several minutes, followed by neutralization with sodium carbonate ${ }^{(6)}$. The effect of this pretreatment is remarkable as is clearly seen in Fig. 4. Glass fibers are chemically etched away from the surface to the depth of about 100 micrometers.

In addition to the process above mentioned, the rolling contact surfaces of the bearing elements were covered with sputtered PTFE. The aim of the coating
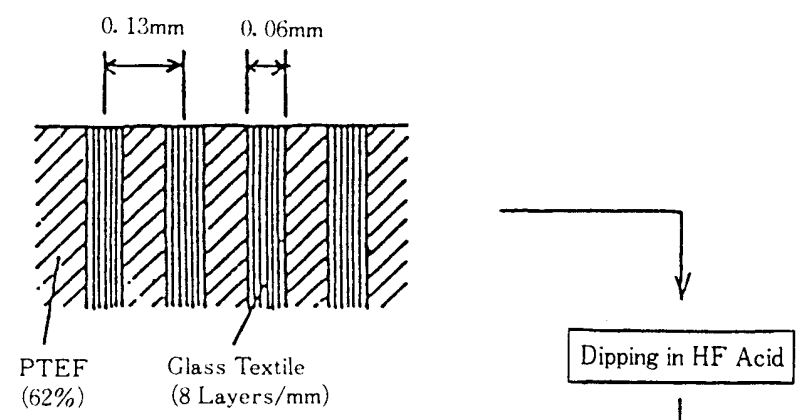

(a) before acid treatment

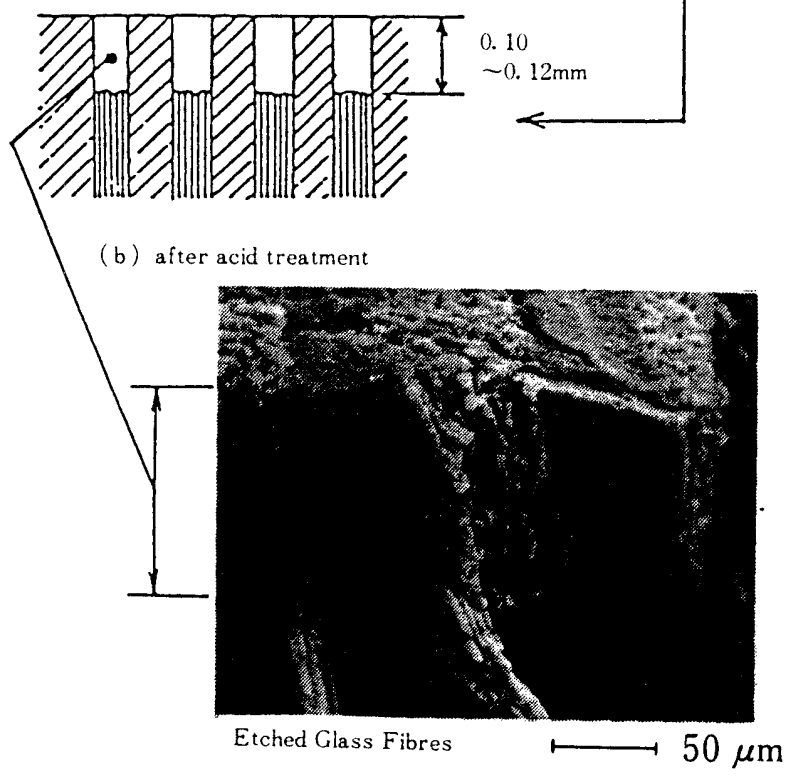

Fig. 4 Acid treatment of a cage material ${ }^{(6)}$ is twofolds: to induce smooth running-in and to protect surfaces from possible attack from acid remaining in the small pores of etched surfaces.

By introducing these new techniques, trouble-free operation of an LE- 5 engine became a reality. These new techniques are to be adopted in the LE-7 engine.

\subsection{Seals}

The role of a mechanical seal is to achieve the least leakage from the high pressure side to the low pressure side through sliding surfaces. The mechanical seals in the $\mathrm{LH}_{2}$ turbopumps of an LE-5 engine are probably the most critical ones: they are forced to rotate at the speed of $113 \mathrm{~m} / \mathrm{s}$ under the pressure of 1.37 $\mathrm{MPa}$ maintaining the minimum lealage of liquid hydrogen. When one wants to keep leakage to the minimum, one should apply high load to the seal surface but this gives rise to the increase in wear. Decreasing seal pressure induces leakage increase because the viscosity of liquid hydrogen is as low as that of gaseous air. Moreover, the thermal strain of seal surfaces caused by friction leads to the leakage increase. Accordingly, careful selection of a material combination and cautious adjustment of design parameters are needed.

For the $\mathrm{LH}_{2}$ turbopump of an LE-5 engine, the selected combination of a seal ring and a mating ring was hard carbon and a hard chrome coating. Figure 5 indicates the leakage characteristics of the mechanical seal tested ${ }^{(7)}$. This combination exhibited stable hydrogen gas leakage of about 6 to $15 \mathrm{N1} / \mathrm{min}$ after 50 minutes' operation at $50000 \mathrm{rpm}$.

Requirements for the seals of a LOX turbopump are more stringent than those for a $\mathrm{LH}_{2}$ turbopump, as already mentioned. A combination of a mechanical seal, a segment seal and a helium gas purge seal,

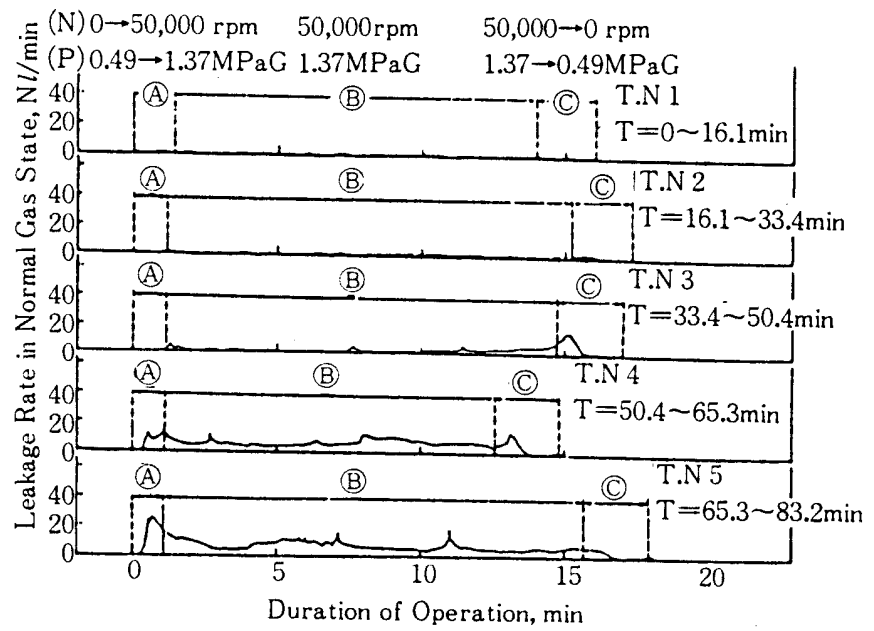

Fig. 5 Change of leakage rate during durability test ${ }^{(7)}$ (Spring force : $36 \mathrm{~N}$, Rotational speed : $50000 \mathrm{rpm}$ ) Operating sealed pressure : $137 \mathrm{MPa}$ 
shown schematically in Fig. 6 was the answer to this difficult problem ${ }^{(8)}$. Figure 7 gives temperture and pressure change of the seal system obtained during the endurance test. After 117 minutes' operation, the wear of the seal surfaces was measured and found to be within acceptable limits: the crbon ring wear was 5 to 8 micrometers, the mating ring wear was 5 to 15 micrometers, and two gas seals produced wear of 5 to 15 micrometers for carbon sides and 0.5 micrometer for seal runner sides.

Based on the experience accumulated during the

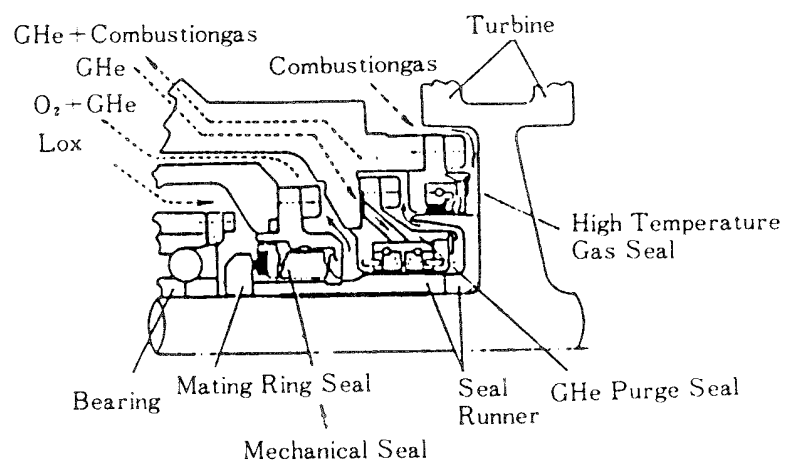

Fig. 6 Rotating-shaft seals of an LE-5 LOX engines ${ }^{(8)}$
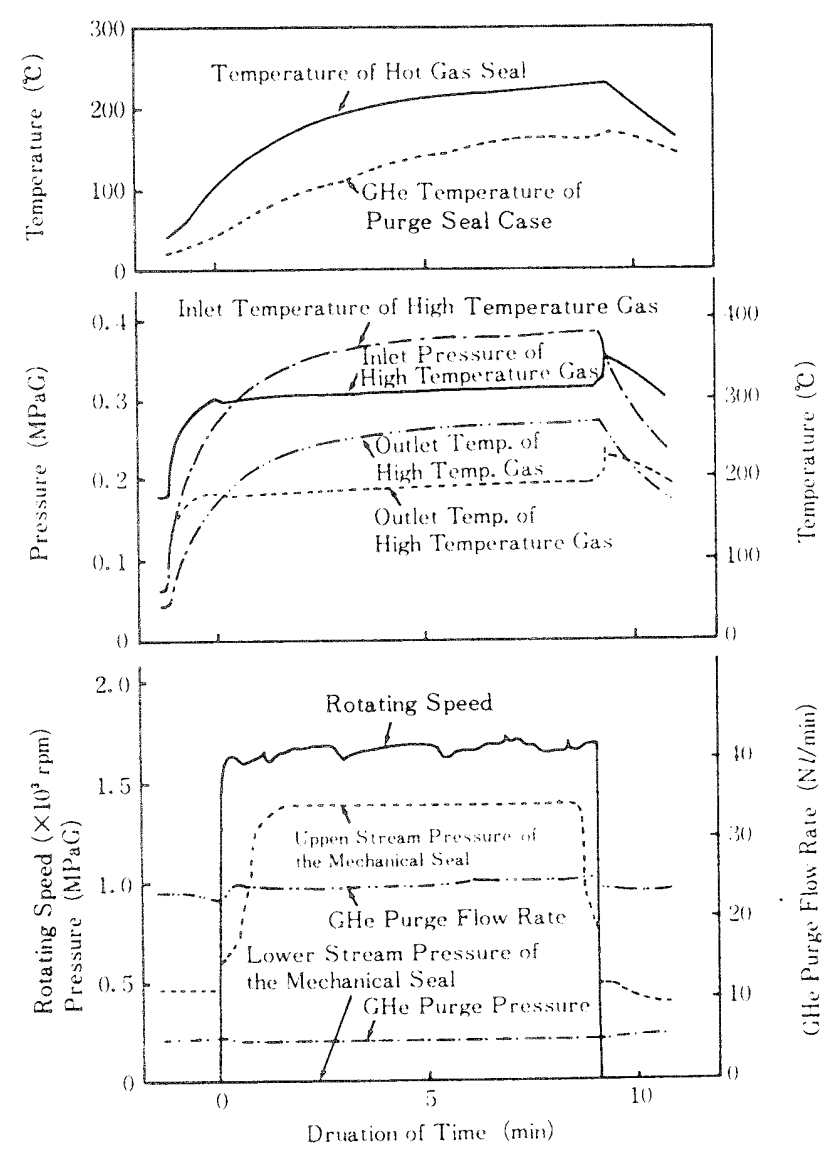

Fig. 7 Results obtained from the endurance test of an LOX turbopump $^{(8)}$
$R \& D$ of the $L E-5$ engine, studies on the sealing system for the LE-7 engine commenced in 1984. A schematic diagram of the seals for a Lox turbopump being tested is shown in Fig. $8^{(9)}$. The sealing system being developed for an LE-7 is different from that for an LE-5 in that it employs a low temperature, high pressure hydrogen gas seal between the turbine disk and the shaft seals instead of sealing the combustion gas directly by the floating ring seals. The thermal strain of the floating ring seals was eased considerably by this design change, but gave rise to another difficulty: the smooth movement of the carbon seal was disturbed by the axial force imposed on the seal surface by the high pressure differencial. To maintain free radial displacement, the surface of the carbon seal was sputter-coated with molybdenum disulfide. A tapered allowance between the shaft and the face seal was effective in reducing the seal load.

\section{Satellites}

The Japanese Satellite Program in the $1990 \mathrm{~s}$ is outlined in Table 3. Japan plans to launch, on average, two satellites per year ${ }^{(9)}$. In contrast to mechanical components used in the launch vehicles, for many years, the importance of the $\mathrm{R} \& \mathrm{D}$ of mechanisms for satellites failed to attract much attention. Nevertheless, fundamental studies on friction, wear and lubrication of machine elements for space use has continued for more than twenty years. It was not until recently that the importance of space tribology was highlighted when the scanning mirror of the meteorological satellite now in operation malfunctioned, possibly due to the build-up of molybdenum disulfide debris deposited on the balls and races of the supporting bearings of the scanner.

\section{1 Rolling Bearings}

Satellites have various mechanical components that need lubrication. Moving parts applied to a satellite are divided roughly into two extreme cases: those parts required to take only one single action in orbit

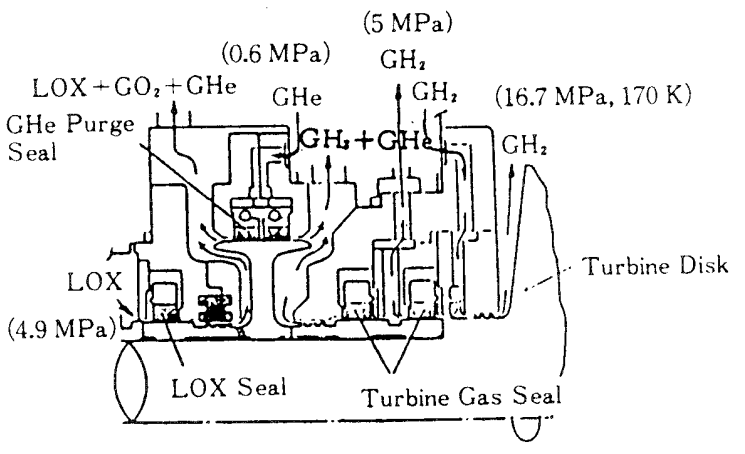

Fig. 8 Rootating-shaft seal of the LOX turbopump for an LE- 7 engine (under development) ${ }^{(9)}$ 
Table 3 Japanese satellite program to $1990 \mathrm{~s}^{(9)}$

\begin{tabular}{|c|c|c|c|c|}
\hline $\begin{array}{l}\text { L.V. } \\
\text { F.Y. }\end{array}$ & $\begin{array}{l}\text { M Vehicle } \\
\text { For } \\
\text { Scientific } \\
\text { Missions }\end{array}$ & $\begin{array}{l}\mathrm{H}-1 \\
\text { Vehicle } \\
550 \mathrm{~kg} \\
\text { into g. o. }\end{array}$ & $\begin{array}{l}\mathrm{H}-\text { II } \\
\text { Vehicle } \\
2 \text { ton } \\
\text { into g. o }\end{array}$ & $\begin{array}{l}\text { U.S. } \\
\text { Space } \\
\text { Shuttle }\end{array}$ \\
\hline '87 & & $\Delta C S-3 a$ & & \\
\hline '88 & AEXOS-D & $\Delta C S-3 b$ & & \\
\hline '89' & $\triangle$ MUSES - A & $\triangle G M S-4$ & & \\
\hline '90' & & $A B S \cdot 3 a$ & & $\begin{array}{l}\triangle I M L \\
\triangle S E P A C\end{array}$ \\
\hline '91 & & $\begin{array}{l}\text { AERS - } 1 \\
\text { ABS - 3b }\end{array}$ & $\Delta \mathrm{H}$ - II Test Flight & AFMPT \\
\hline 92' & & & $\begin{array}{l}\triangle E T S-\text { VI } \\
\text { ASFU }\end{array}$ & A GEOTAIL. \\
\hline
\end{tabular}

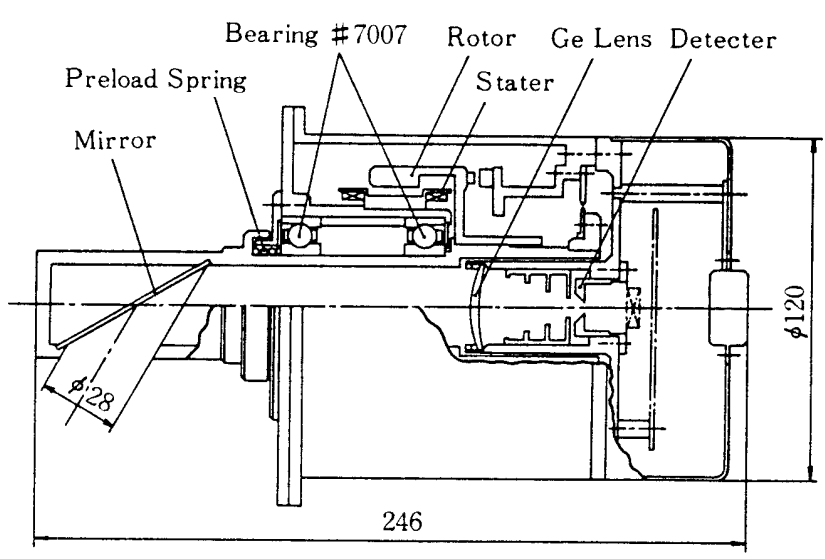

Fig. 9 Earth sensor tested in space ${ }^{(10)}$

and those expected to operate for the lifetime of a satellite, the latter demanding in most cases solid lubricated ball bearings as moving elements.

The earth sensor shown in Fig. 1 is used to confirm the relative location of a satellite to the earth by catching infrared rays emitted from the earth surface. This type of earth sensor, shown schematically in Fig. $9^{(10)}$, was launched as a paylead of the Engineering Test Satellite (ETS) IV in February $1981^{(10)}$. According to Ikeuchi et al., they operated for more than 4000 hours on orbit, with most of the flight being completed at lower than $10^{-10} \mathrm{~Pa}^{(10)}$. The operation accompanied the measurement of friction torque and motor temperature. The result taken during the flight from February 1981 to April 1982 is given in Fig. 10. As the ETS IV ${ }^{(11)}$ was spin-stabilized, it was equipped with two earth sensors; one at center and the other on the outside. The latter received the acceleration of

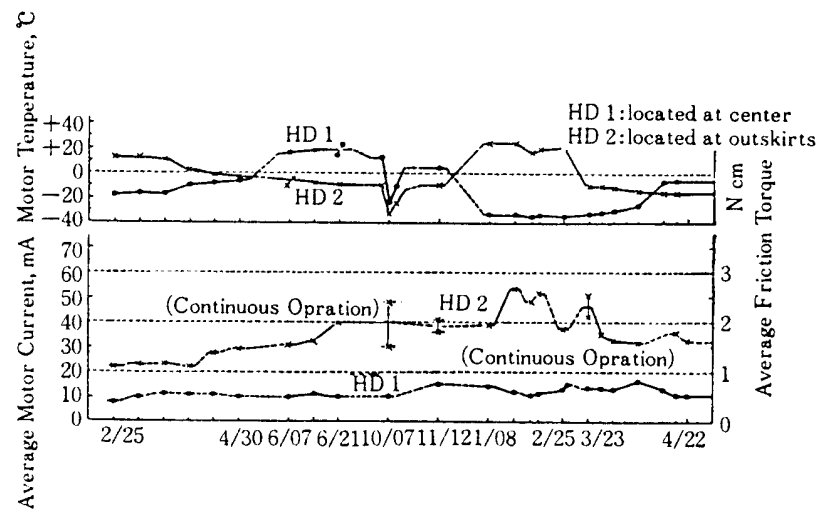

Fig. 10 Temperature and average friction torque change of earth sensors operated in space from february 1981 to April $1982^{(11)}$

$3.5 \mathrm{~g}$ induced by spinning at $60 \mathrm{rpm}$. As a result, this sensor exhibited the friction torque of 1.08 to $2.6 \mathrm{Ncm}$, while the former indicated the average torque of 0.39 to $0.78 \mathrm{Ncm}$ throughout the operation.

The cage material selection test for the earth sensor was conducted by Miyakawa et al. ${ }^{(11)}$. Table 4 presents the lifetime of ball bearings using candidate cages. Although the best result was obtained with the bearings lubricated by the combination of Rulon $\mathrm{E}$ cages and sputtered $\mathrm{MoS}_{2}$ films on balls and races, the bearings actually used in flight were lubricated by PTFE coatings and Rulon $C$ cages for fear that an $\mathrm{MoS}_{2}$ film would be worn off during tests conducted on earth before the launch. Laboratory tests indicated that the friction and wear of Rulon $C$ cages was intrinsically better in air than in a vacuum as shown in Fig. 11; they exhibited rather high and unstable friction characteristics after a short period when operat- 
ed in vacuo ( Fig. 12).

\section{2 Magnetic Bearings}

Compared to conventional contact-type bearings, noncontact-type such as magnetically supported ones have the advantage of being able to eliminate friction and wear. A major drawback is its low load carrying

Table 4 Life time of candidate cage materials for the earth sensor tested in a vacum and in air ${ }^{(11)}$

\begin{tabular}{|c|c|c|c|}
\hline \multirow[t]{2}{*}{ cage material } & \multirow{2}{*}{$\begin{array}{l}\text { coating on } \\
\text { balls and races }\end{array}$} & \multicolumn{2}{|c|}{ life time, hr } \\
\hline & & vacuum & air \\
\hline rulon LD & (PTEF sprayed) & 30 & 161 \\
\hline rulon $A$ & (PTFE sprayed) & 137 & 247 \\
\hline A & $\left(\mathrm{MoS}_{2}\right.$ sputtered) & 948 & \\
\hline $\mathrm{A}+2 \% \mathrm{MoS}_{2}$ & $\left(\mathrm{MoS}_{2}\right.$ sputtered) & 1194 & \\
\hline rulon $\mathrm{C}$ & (PTFE sprayed) & 190 & $>20000$ \\
\hline rulon $\mathrm{J}$ & (PTFE sprayed) & 47 & 24 \\
\hline rulon $E$ & $\left(\mathrm{MoS}_{2}\right.$ sputtered) & $>5000$ & \\
\hline Meldin 5518 & $\left(\mathrm{MoS}_{2}\right.$ sputtered) & 10 & 1.5 \\
\hline
\end{tabular}

tested bearing type : $\$ 7204$ and $7204 \mathrm{C}$, axial load: $50 \mathrm{~N}$ rotating speed : $2,000 \mathrm{rpm}$

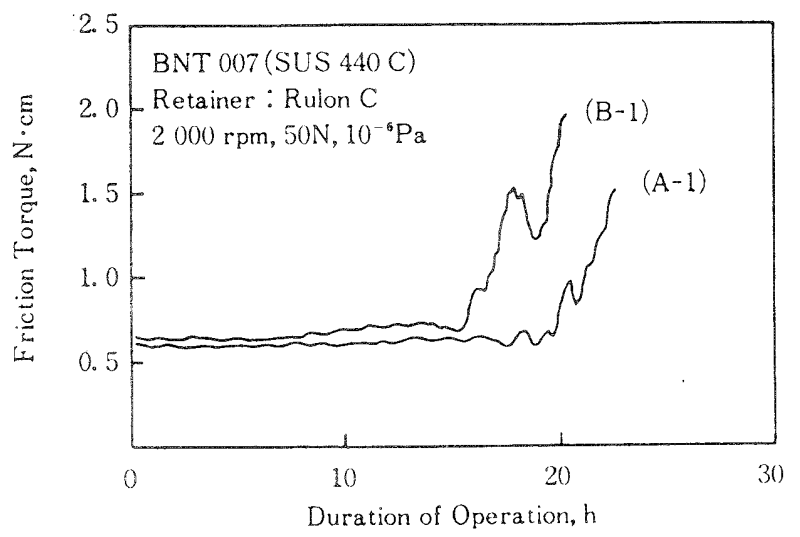

Fig. 11 Change of friction torque of ball bearings in a vacuum using rulon $\mathrm{C}$ retainers

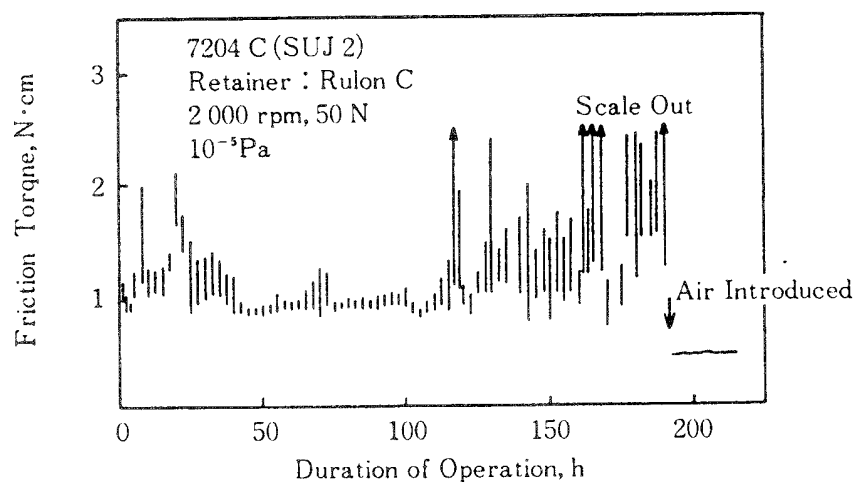

Fig. 12 Change of friction torque of a ball bearing by introducing air capacity which one need not consider when one intends to adopt it for space use. Magnetically supported bearings are inherently suitable for zero gravity conditions.

For years, Murakami and Nakajima have been engaged in the study of magnetic bearings aimed at realizing a magnetically supported flywheel for threeaxis controlled satellites. Their efforts bore fruit.

In 1985 , the first $\mathrm{H}-\mathrm{I}$ vehicle succeeded in operating a magnetic flywheel system in space. Figures 13 and 14 show the schematic diagram and the appearance of the magnetic flywheel tested ${ }^{(12)}$.

Magnetic bearings controlled by direct current can be divided into five groups according to the number of actively controlled axes. One can control the dynamic behavior of a magnetic bearing more quickly and precisely by increasing the number of controlled axes. But this in turn involves complexity, increased weight, increased power and decreased reliability, all of which are unacceptable for a space craft. So they selected a simple two-axis type.

The flight model was operated at $1000 \mathrm{rpm}$ intermittently for three days untill the battery on board was completely discharged. Figure 15 describes one of the results obtained ${ }^{(13)}$. The change in position of the axes was measured on earth and in space. The dis-

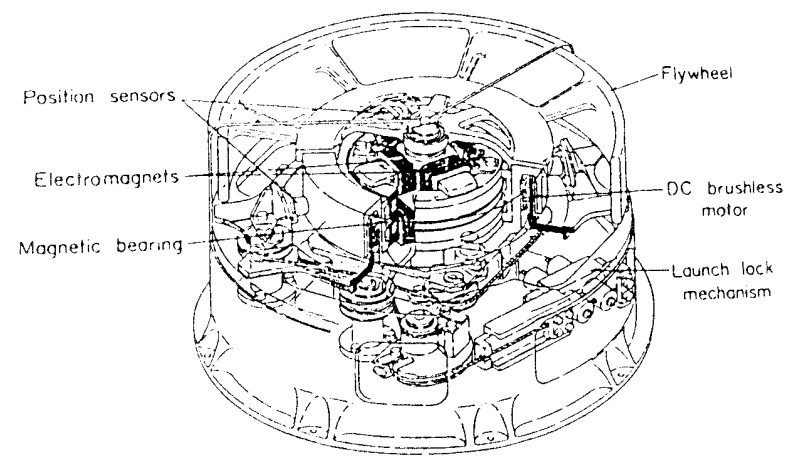

Fig. 13 Magnetically supported flywheel tested in space ${ }^{(12)}$

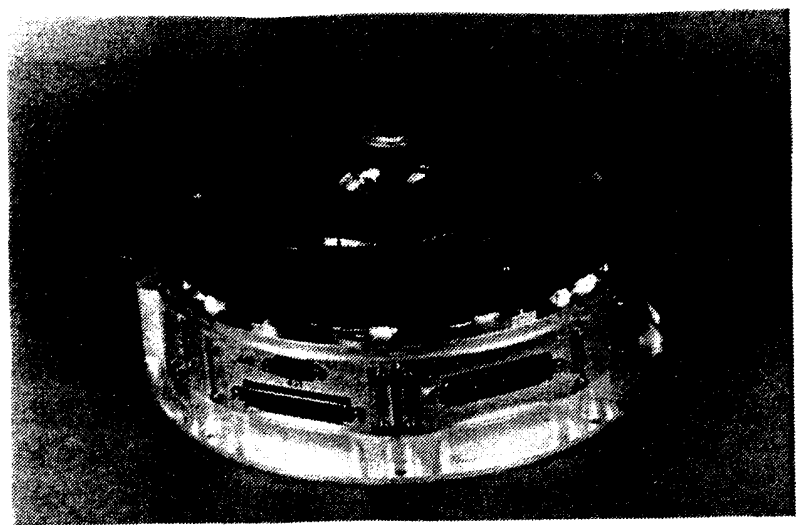

Fig. 14 Magnetically supported flywheel tested in space ${ }^{(12)}$ 
placement of the $\mathrm{x}$ and $\mathrm{y}$ axes remained essentially the same before and after the launch, while the wheel rose $0.22 \mathrm{~mm}$ in space from the original position on earth, because of the absence of gravity.

\section{Future View}

Japan decided in 1985 to join the Space Station Program announced by U. S. President Ronald Reagan. The main area of participation consists of constructing the Japanese Experiment Module (JEM) presented schematically in Fig. $16^{(14)}$ and the conducting of physical, chemical and biological experiments principally by Japanese astronauts.

The intensive R \& D of.the JEM is being done by the National Space Development Agency. Designers engaged in the work specified various requirements for the lubrication systems : an example is shown in

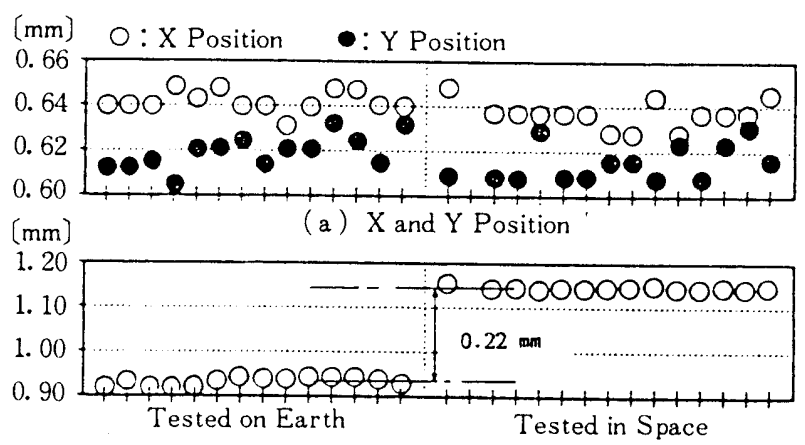

(b) Z-Position

Fig. 15 Position changes of the the flywheel axis measured on earth and in space ${ }^{(13)}$
Fig. 17. It shows the pressure-velocity-life relationship required of the solid lubricant films for the JEM. Most of the requirements fall into the category that any existing solid lubricant films for space use can fulfill. However, some are without doubt out of the range that even the most advanced solid film could satisfy. Research should be conducted to develop new solid lubricant films which will meet the requirement.

Other major problems confronting tribologists are;

(1) Long-term lubrication system are needed that the present space tribology can not offer.

(2) Lubricants with high load carrying capacities are required.

(3) Lubricants to be exposed to space should be atomic oxygen resistant.

Of particular interest is the fact that the atmosphere at the flight altitude of the Space Station is mainly composed of atomic oxygen which seems to be so active that no organic material can survive without injuring of some kind when exposed to outer space for more than ten years. Organic compounds have been widely used as solid lubricants or as binders of solid lubricating materials for use in space. Most solid lubricants, including molybdenum disulfide, are also likely to suffer from exposure to atomic oxygen with the exception of oxides and gold. Thus emphasis should be placed on the following studies: first to ascertain the degree of damage on the lubrication properties of solid lubricants exposed to atomic oxy.

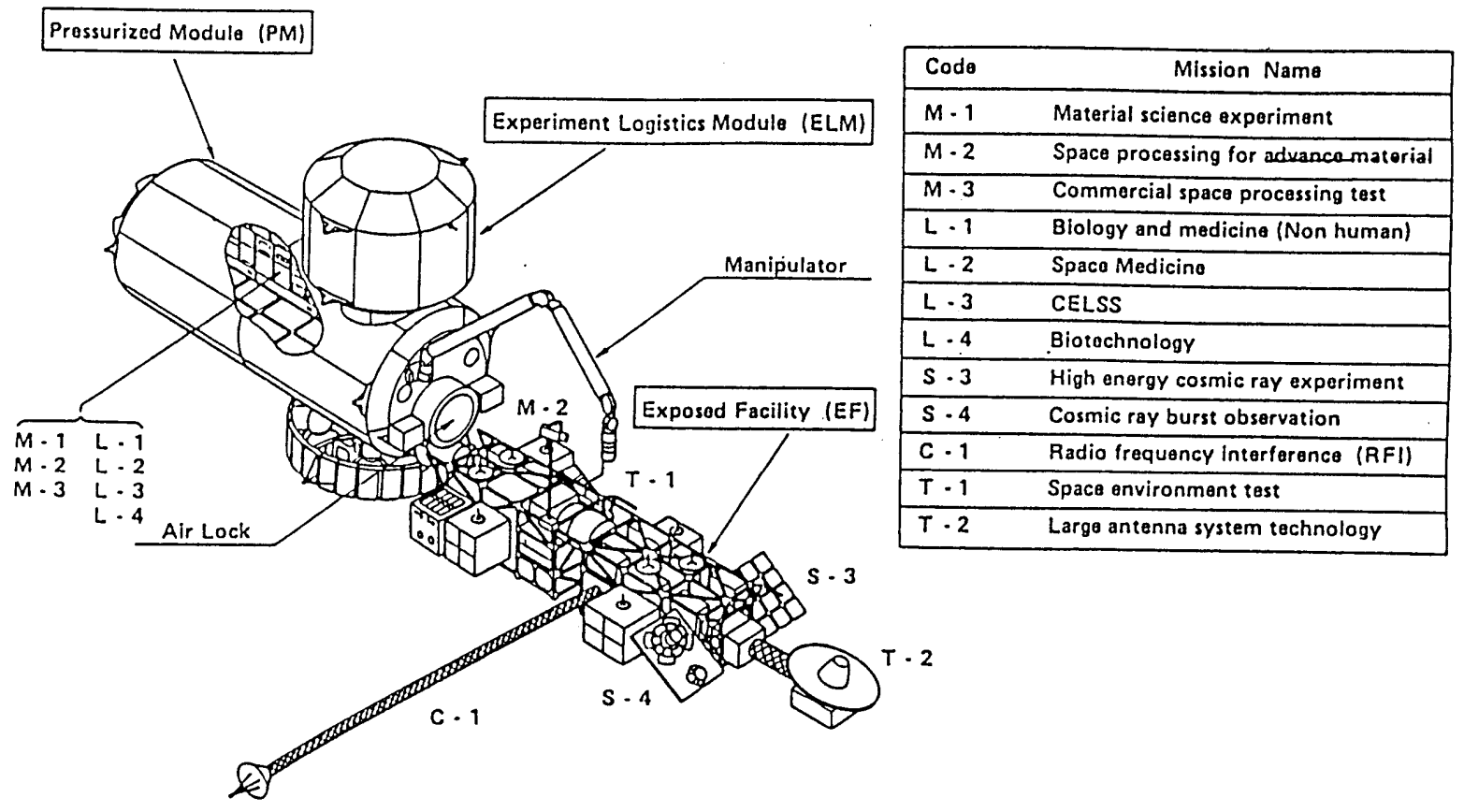

Fig. 16 JEM baseline configuration and payload accommodation ${ }^{(9)}$ 


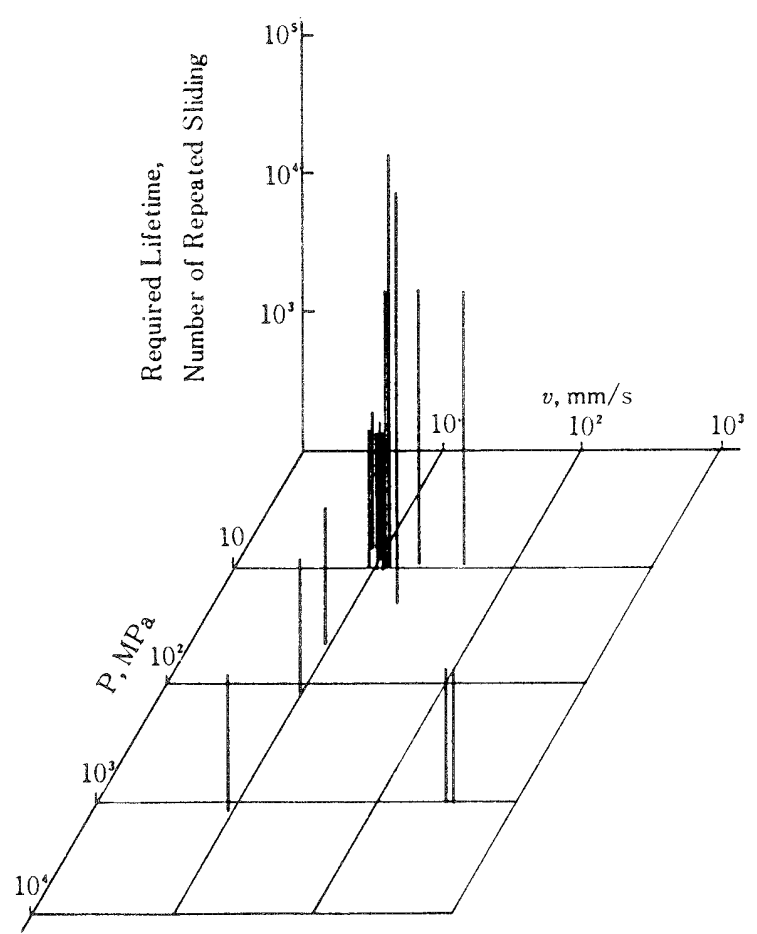

Fig. 17 Required conditions to solid lubricont films to be applied to the Japan Experiment Module

gen with or without ultraviolet rays emitted from the sun, and second, to develop alternatives if the damage is serious. For this purpose, the development of an atomic oxygen generator is needed as soon as possible.

\section{Acknowledgement}

The author wishes to express his appreciation to his colleagues, Drs. M. Nosaka and A. Nakajima, for their assistance in completing the article.

\section{References}

(1) Pamphlet on the Activities of the National Space Development Agency in 1984, National Space
Development Agency (in Japanese), (1985).

(2) ibid

(3) Nakanishi, H., Development of the Launch Vehicles in Japan, Appl. Mech. Eng., (in Japanese), No. 1 (1981), p. 44.

(4) Nosaka, M., Tribology at Cryogenic Temperatures, Tribology, (in Japanese), Vol. 1, No.12 (1987), p. 4.

(5) Nosaka, M., Rolling Bearings and Shaft Seals of Turbopumps for a Rocket Engine, Turbo Machinery, (in Japanese), Vo 1.15, No. 6 (1987), p. 351.

(6) Nosaka, M., Oike, M., Kamijo, K. and Kikuchi, M., Experimental Study on Lubricating Performance of Self-Lubricating Ball Bearings for Liquid Hydrogen Turbopumps, Lubr. Eng., Vo 1.44, No. 1 (1988), p. 30.

( 7 ) Suzuki, M., Nosaka, M., Kamijo, K. and Kikuchi, M., Research and Development of a RotatingShaft Seals for a Liquid Hydrogen Turbopump, Lubr. Eng., Vo 1. 42, No. 3 (1986), p. 162.

(8) ref. (5).

(9) Pamphlet of the Science and Technology Agency, Japan, Science and Technology Agency (1987).

(10) Ikeuchi, M., Wakabayashi, Y., Murakami, C., Ohkami, Y. and Kida, T., Evaluation of the Bearing System Using Solid Lubricant of Scanning Earth Sensor on Engineering Test Satellite IV, J. JSLE, (in Japanese), Vo 1.28, No. 9 (1983), p. 649.

(11) Miyakawa, Y., Nishimura, M. and Seki, K., Performance of Ball Bearings Lubricated with SelfLubricating Cages, Prepr. of Tohoku Conf. JSLE, (in Japanese), (1982), p. 177.

(12) Nakajima, A., Yamaguchi, I., Fujiwara, T., Sakurai, Y., Kimura, T., Kumagai, T., Toyokawa, M. and Murakami, C., Experimental Results of OnBoard Test of a Magnetic Bearing Using the Satellite "Jindai", Prepr. of 31 st Integr. Conf. on Space Sci., (in Japanese), JSAS (1987), p. 236.

(13) Nakajima, A., Sato, I. and Shinozaki, H., Research and Development of Magnetic Bearings Having a Passively Stabilized Shaft, Prep. Meet. Linear Drive LD-88-4, (in Japanese), (1988).

(14) Ref.(9). 